\title{
A Retrospective Study on Incidence of Maxillary Carcinoma in A University Setting
}

\section{Nivetha $\mathbf{G}^{1}$, Kathiravan $\mathbf{S}^{2}$, Arvind $\mathbf{S}^{3}$}

Section: Healthcare

Sci. Journal Impact

Factor: $6.1(2018)$

ICV: 90.90 (2018)

(c) (i) (8)

Copyright@IJCRR

\begin{abstract}
'Saveetha Dental College and Hospitals, Saveetha lnstitute of Medical and Technical Science, Saveetha University, Chennai, India; ${ }^{2}$ Senior Lecturer,Department of Oral and Maxillofacial Surgery, Saveetha Dental College and Hospitals, Saveetha Institute of Medical and Technical Science, Saveetha University, Chennai, India; ${ }^{R}$ Reader, Department of Orthodontics, Saveetha Dental College and Hospitals, Saveetha Institute of Medical and Technical Science, Saveetha University, Chennai, India.
\end{abstract}

\section{ABSTRACT}

Introduction: Oral cancer is considered as one of the major life threatening public health issues on a global scale. Oral cancer is ranked as the sixth most common cancer. Chewing tobacco/pan masala is considered to be the most potent risk factor for oral precancerous lesions and oral cancer.

Objective: The aim of this study is to find out the incidence of maxillary carcinoma among oral cancer patients visiting Saveetha dental college.

Methods: The study was carried out in Saveetha Institute of Oral Oncology at Saveetha Dental College and Hospitals. The data were collected from case records of patients who visited the unit, between July 2019 - March 2020 and entered in Excel sheets. The entered data were subjected to statistical analysis using SPSS software version 26.

Results: Among 30 carcinoma patients, 8 patients had maxillary carcinoma which accounted for an incidence rate of $26.67 \%$. Males and females were equally affected. Maxillary carcinoma was most noted in the age group 41-50 [50.00\%] followed by 5160 age group [25.00\%]. Statistically significant association was found between gender and maxillary carcinoma $(p-v a l u e=0.037)$ whereas it was not statistically significant between age and maxillary carcinoma ( $p$-value=0.766).

Conclusion: Incidence of maxillary carcinoma reported was $26.7 \%$, with equal gender predilection and most common in the 4 th decade of life.

Key Words: Age, Gender, Incidence, Maxillary carcinoma

\section{INTRODUCTION}

Oral cancer is a malignant disease affecting oral tissues, such as lip, floor of the mouth, buccal mucosa, gingiva, palate and tongue. ${ }^{1}$ India has the world's highest number of oral cancer cases approximately $20 \%$, with an estimated $1 \%$ of the population having premalignant lesions. ${ }^{2}$ Approximately $95 \%$ of oral cancer occurs in people older than 40years with an average age of 60years. ${ }^{3}$ Factors such as tobacco chewing, alcohol consumption, human papillomavirus 16 and 18, Humanimmunodeficiency virus infection[HIV], dietary factors and genetics factors are considered as etiological factors for oral cancer. Clinically, oral cancer appears as red or white lesion, proliferative or ulcerative growth, most commonly affecting the site of tobacco pouching such as the buccal mucosa, alveolar mucosa and lip. ${ }^{4}$
The majority of oral cancers are squamous cell carcinoma which is arising from pre-existing potentially premalignant lesions. ${ }^{5}$ Oral squamous cell carcinoma [OSCC] accounts for $90 \%$ of malignant oral lesions and is widely recognized as the most commonly occurring malignant tumor of oral structures, and the mortality rate of OSCC is relatively high, with a 5 -year survival rate of $50 \%{ }^{6,7}$ Tobacco consumption is a major risk factor for oral and oropharyngeal SCC. ${ }^{8}$ The most common sites of occurrence of oral squamous cell carcinoma [OSCC] due to smokeless tobacco are buccal mucosa and tongue. ${ }^{9}$ Oral submucous fibrosis is an insidious, chronic disease and it is characterized by blanching and stiffness of the oral mucosa which results in limited mouth opening and intolerance to hot and spicy food. ${ }^{10}$ It is most commonly seen in the Indian subcontinent with prevalence in South East

\section{Corresponding Author:}

Kathiravan Selvarasu, Senior Lecturer, Department of Oral and Maxillofacial Surgery, Saveetha Dental College,Saveetha Institute of Medical and Technical Science, Saveetha University, Chennai, India; 162, PH road, Chennai-600077, Tamilnadu, India; Contact: 9677202463; Email: kathiravan.sdc@saveetha.com

ISSN: 2231-2196 (Print) ISSN: 0975-5241 (Online)

Received: 18.09 .2020

Revised: 19.10 .2020

Accepted: 16.11 .2020

Published: 26.12 .2020 
Asia ranging from $0.04-24.4 \%{ }^{11}$ The consumption of areca nuts is the main etiological factor. ${ }^{12}$

Maxillary carcinoma is best managed by a team of healthcare professionals and reviewed by a tumor board, consisting of pathologists, radiologists, surgeons, radiation oncologists and medical oncologists..$^{13,14}$ Malignant tumors of the maxillary sinus are rare neoplasms that account for approximately $3 \%$ of head and neck cancer and $0.5 \%$ of malignant disease. The annual incidence of maxillary sinus cancer is $0.1-1.0 \%$ case per 100,000 of the population Smoking and chronic sinusitis are the most common risk factors for maxillary sinus cancer. In addition occupational exposure to chemical substances such as formaldehyde, chromium, nickel, and air pollution is associated with an increased risk for malignant tumors of maxillary sinus. It rarely present with symptoms at an early stage as many lesions are asymptomatic until they become quite large. ${ }^{15}$

Previously our team had conducted numerous clinical trials ${ }^{16,17}$, in vitro studies ${ }^{7,10,18-21}$ and surveyed ${ }^{14,22-25}$, and reviewed ${ }^{26,27}$ various aspects of oral and maxillofacial surgery over the past five years. Now we are focusing on retrospective studies, the idea for which has stemmed from the current interest in our community. The aim of the study is to find out the incidence of Maxillary carcinoma among the small population at visiting the Saveetha Dental College.

\section{MATERIALS AND METHOD}

\section{Study population}

A retrospective study was carried out in the Saveetha Institute of Oral Oncology at Saveetha Dental College and Hospitals. The data was collected from the period of June 2019-March 2020.

\section{Inclusion criteria}

Tumors involving maxilla; i.e. Oral Squamous cell carcinoma and carcinoma of maxillary antrum.

\section{Exclusion criteria}

People with Diabetes

People less than 18 years of age

Physically challenged

Patient who underwent previous radiotherapy and chemotherapy treatment

\section{Ethical approval}

Ethical approval was obtained from the Institutional Ethical Committee and Scientific Review Board of Saveetha Dental College: SDC/SIHEC/2020/DIASDATA/0619-0320.

\section{Data collection}

The data was collected using the patients' records between July 2019 - March 2020. The data comprises of 30 cancer patients. The data collected includes patient's age, gender, and type of oral cancer.

\section{Statistical analysis}

The data collected were entered in excel sheets and defined for statistical analysis using SPSS software. A chi square test was done between age and maxillary carcinoma and gender and maxillary carcinoma. The independent variables were age and gender whereas the dependent variable is maxillary carcinoma. The results were formulated in Graphs.

\section{RESULTS}

The charts and the records from the oncology department identified 30 patients who were diagnosed with OSCC, among which $26.7 \%$ had maxillary [Graph 1]. Both genders were equally affected with maxillary carcinoma with 4 females [50.00\%] and 4 males [50.00\%] [Graph 2]. The mean age of the patient was 50 years [ranging from 32-68 years]. The highest incidence was seen in the age group of 41-50 years i.e., 4 patients [Graph 3]. Chi square analysis proved that association between age and oral carcinoma was not statistically significant [p-value $=0.766]$ [Graph 4] and association between gender and oral carcinoma was also found to be statistically significant [p-value $=0.037$ ] [Graph 5].

\section{DISCUSSION}

From the study we found that maxillary carcinoma accounted for $26.7 \%$ among the sample size of 30 [Graph 1]. Among 8 maxillary carcinoma patients males and females were equally affected [Graph 2]. A study done among Mexican population by Gaitan et al. concludes that oral squamous cell carcinoma has increased in Mexicans females in the last 20 years [1.1:1] which is dissimilar to our present study. ${ }^{28}$ The study conducted by Ajay et al. ${ }^{29}$ and Tandon et al. ${ }^{30}$ had increased male dominance among study population which is opposing to our present study. Association between gender and maxillary carcinoma patients was found to be statistically significant [Graph 5]. Regarding the age group affected 41-50 years was maximum affected followed by 51- 60 years [Graph 3]. The study conducted by Udhaya Kumar et al. ${ }^{31}$ showed that incidence of both benign and malignant tumors of maxilla was highest in the 51-60 years age group which is dissimilar to our present study. Association between age and maxillary carcinoma was found to be statistically not significant [Graph 4]. This difference in results in comparison with other studies could be due to relatively smaller sample size. 
Males are more affected than females and most of the patients present with locally advanced tumors. The presenting symptoms of patients with maxillary carcinoma are pain, oral symptoms, facial swelling, nasal obstruction, and epistaxis. ${ }^{32}$ Prognosis of maxillary carcinoma was described by using Öhngren's line, which joins the medial canthus of the eye to the angle of the mandible. This plane divides the region of the nasal cavity and maxillary antrum into two halves; i.e. infrastructure and suprastructure. In patients with lesions arising from the infrastructure, symptoms generally develop early during the course of the disease while in patients with lesions arising from suprastructure, symptoms develop late. Carcinoma appearing in the suprastructure have relatively better prognosis as compared to the ones in infrastructure. Surgical resection is the initial treatment of choice for most tumors of the maxilla, nasal cavity and paranasal sinuses, although induction chemotherapy and concurrent chemoradiation therapy may be considered for very advanced tumors preoperatively or postoperatively. Lesions staged as T4b according to TNM staging are considered unresectable and radiation with chemotherapy may be employed as definitive treatment. $^{33}$

A contraindication to surgical intervention for advanced tumors of the nasal cavity and paranasal sinuses includes the presence of trismus, invasion of the cavernous sinus with cranial nerve paralysis and invasion of carotid arteries by the tumor. ${ }^{34}$ Early-stage [-I and -II] oral squamous cell carcinoma can be treated with surgery or radiation. The primary site is treated mostly through a peri-oral approach and wide local excision of the tumor with a clinical margin of one centimeter of healthy surrounding tissue. Addition Of chemo-radiotherapy regimen in the postoperative setting is quite rare and depends mainly on the presence of adverse histopathological features. ${ }^{17,21,35}$ Advanced-stage [-III and -IV] oral squamous cell carcinoma, a combination of surgery and radiation therapy provides the best survival rate, although this increases the complications and morbidity. ${ }^{36}$

\section{Limitations}

The main limitation of this study is specific geographic location and confined to limited sample size. This is corrected by conducting the study in different states, different universities to get more results.

\section{CONCLUSION}

From this study, we could conclude that the incidence of maxillary carcinoma was $26.67 \%$, with no gender predilection and it was most commonly noted in the 4th decade of life. Early diagnosis and treatment help to reduce the morbidity and mortality rates, as well improves the life expectancy of patients affected with maxillary carcinoma.

\section{Author Contributions}

First author [Nivetha G] performed analysis, interpretation, and wrote the manuscript. Second author [Dr.Kathiravan Selvarasu] contributed to conception, data designs, analysis, interpretation, and critically revised the manuscript.

Third author [Dr. Arvind Sivakumar] participated in the study and revised the manuscript. All the three authors have discussed the results and contributed to the final manuscript.

\section{ACKNOWLEDGEMENT}

I sincerely express my gratitude and acknowledgement to Dr. Kathiravan and Dr. Arvind Sivakumar and Dean and management for their support and also thank the Research and IT department of Saveetha dental college for their affable assistance in analyzing the data.

\section{Conflict of Interest: Nil}

\section{REFERENCES}

1. Ariyoshi Y, Shimahara M, Omura K, Yamamoto E, Mizuki H, Chiba H, et al. Epidemiological study of malignant tumors in the oral and maxillofacial region: survey of member institutions of the Japanese Society of Oral and Maxillofacial Surgeons, 2002. Int J Clin Oncol 2008;13[3]:220-8.

2. Chaturvedi P, Chocolatewala N. Role of human papilloma virus in the oral carcinogenesis: An Indian perspective. J Cancer Res Therap 2009;5:71.

3. Mashberg A, Samit AM. Early detection, diagnosis, and management of oral and oropharyngeal cancer. CA Cancer J Clin 1989;39[2]:67-88.

4. Fazeli Z, Pourhoseingholi MA, Pourhoseingholi A, Vahedi M, Zali MR. Mortality of oral cavity cancer in Iran. Asian Pac J Cancer Prev 2011;12[10]:2763-6.

5. Bhurgri Y, Bhurgri A, Hussainy AS, Usman A, Faridi N, Malik J, et al. Cancer of the oral cavity and pharynx in Karachi-identification of potential risk factors. Asian Pac J Cancer Prev 2003;4[2]:125-30.

6. Balaram P, Sridhar H, Rajkumar T. Oral cancer in southern India: The influence of smoking, drinking, paan-chewing and oral hygiene. J Cancer 2002;98[3]:440-5.

7. Marimuthu M, Andiappan M, Wahab A, Muthusekhar MR, Balakrishnan A, Shanmugam S. Canonical Wnt pathway gene expression and their clinical correlation in oral squamous cell carcinoma. Indian J Dent Res 2018;29[3]:291-7.

8. Jin X, Liu D, Zhao X, Zhou Y, Jiang L, Li J, et al. Analysis of clinicopathological characteristics associated with the outcome of oral squamous cell carcinoma and the establishment of tissue microarrays. Oncol Lett 2016;12[5]:3175-82.

9. Chi AC, Day TA, Neville BW. Oral cavity and oropharyngeal squamous cell carcinoma - an update. CA Cancer J Clin 2015;65[2]:401-21.

10. Patil SB, Durairaj D, Suresh Kumar G, Karthikeyan D, Pradeep D. Comparison of Extended Nasolabial Flap Versus Buccal Fat Pad Graft in the Surgical Management of Oral Submucous Fibrosis: A Prospective Pilot Study. J Maxillofac Oral Surg 2017;16[3]:312-21. 
11. Pindborg JJ, Murti PR, Bhonsle RB, Gupta PC, Daftary DK, Mehta FS. Oral submucous fibrosis as a precancerous condition. Europ J Oral Sci 1984;92:224-9.

12. Pillai R, Balaram P, Reddiar KS. Pathogenesis of oral submucous fibrosis. Relationship to risk factors associated with oral cancer. Cancer 1992;69[8]:2011-20.

13. Werning JW. Oral Cancer: Diagnosis, Management, and Rehabilitation. Thieme 2011;1:368.

14. Kumar S. Relationship between dental anxiety and pain experience during dental extractions. Asian J Pharm and Clin Res 2017; 10:458.

15. Dulguerov P, Jacobsen MS, Allal AS, Lehmann W, Calcaterra T. Nasal and paranasal sinus carcinoma: Are we making progress? Cancer 2001;92:3012-29.

16. Jesudasan JS, Abdul Wahab PU, Muthu Sekhar MR. Effectiveness of $0.2 \%$ chlorhexidine gel and a eugenol-based paste on postoperative alveolar osteitis in patients having third molars extracted: a randomised controlled clinical trial. Br J Oral Maxillofac Surg 2015;53:826-30.

17. Christabel A, Anantanarayanan P, Subash P, Soh CL, Ramanathan M, Muthusekhar MR, et al. Comparison of pterygomaxillary dysjunction with tuberosity separation in isolated Le Fort I osteotomies: a prospective, multi-centre, triple-blind, randomized controlled trial. Int J Oral Maxillofac Surg 2016;45:180-5.

18. Vijayakumar Jain S, Muthusekhar MR, Baig MF, Senthilnathan P, Loganathan S, Abdul Wahab PU, et al. Evaluation of Three-Dimensional Changes in Pharyngeal Airway Following Isolated Lefort One Osteotomy for the Correction of Vertical Maxillary Excess: A Prospective Study. J Maxillofac Oral Surg 2019;18[1]:139-46.

19. Rao TD, Santhosh Kumar MP. Analgesic Efficacy of Paracetamol Vs Ketorolac after Dental Extractions. Res J Pharm Tech 2018;11:3375.

20. Sweta VR, Abhinav RP, Ramesh A. Role of Virtual Reality in Pain Perception of Patients Following the Administration of Local Anesthesia. Ann Maxillofac Surg 2019;9[1]:110-3.

21. Abhinav RP, Selvarasu K, Maheswari GU, Taltia AA. The Patterns and Etiology of Maxillofacial Trauma in South India. Ann Maxillofac Surg 2019;9[1]:114-7.

22. Kumar S, Rahman R. Knowledge, Awareness, and Practices regarding biomedical waste management among undergraduate dental students. Asian J Pharm Clin Res 2017;10:341.

23. Kumar S, Sneha S. Knowledge and awareness regarding antibiotic prophylaxis for infective endocarditis among undergraduate dental students. Asian J Pharm and Clin Res 2016;9:154.

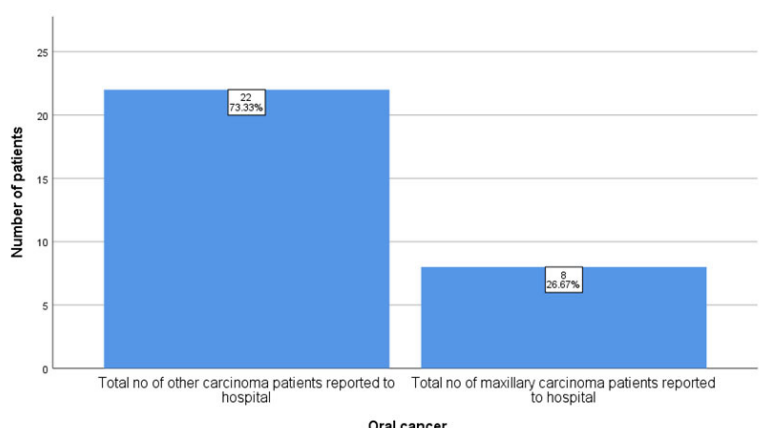

Oral cancer

Graph 1: Bar chart showing the total number of maxillary carcinoma patients reported to hospital. $\mathrm{X}$ axis represents oral carcinoma patients and $Y$ axis represents number of patients. From the Graph we found that $26.67 \%$ patients were reported with maxillary carcinoma.
24. Rahman R, Mp SK. Knowledge, attitude and awareness of dental undergraduate students regarding human immunodeficiency virus / acquired immunodeficiency syndrome patients. Asian J Pharm Clin Res 2017;10[5]:175-80.

25. Patturaja K, Pradeep D. Awareness of Basic Dental Procedure among General Population. Res J Pharm Tech 2016;9:1349.

26. Kumar $\mathrm{S}$. The emerging role of botulinum toxin in the treatment of orofacial disorders Literature update. Asian J Pharm Clin Res 2017;10:21.

27. Packiri S, Gurunathan D, Selvarasu K. Management of Paediatric Oral Ranula: A Systematic Review. J Clin Diagn Res 2017;11[9]:ZE06-9.

28. Gaitán-Cepeda L-A, Peniche-Becerra A-G, Quezada-Rivera D. Trends in frequency and prevalence of oral cancer and oral squamous cell carcinoma in Mexicans. A 20 years retrospective study. Med Oral Pathol Circ Bucal 2011;16[1]:e1-5.

29. Ashwinirani SR, Ajay P, Nayak A, Suragimath G, Kamala KA, Sande A, et al. Oral cancer prevalence in Western population of Maharashtra, India, for a period of 5 years. J Oral Res Rev 2018;10:11.

30. Bordoloi B, Tandon A, Jaiswal R, Srivastava A, Singh R, Shafique U. DemoGraphic and clinicopathological profile of oral squamous cell carcinoma patients of North India: A retrospective institutional study. SRM J Res in Dent Sci 2018;9:114.

31. M. UK, Gouripur K, Elangovan S, Srinivasa V. Clinocpathological study of tumors of maxilla. Int J Otorhinolaryngol Head Neck Surg 2017;3:795.

32. Qureshi SS, Chaukar DA, Talole SD, D’Cruz AK. Squamous cell carcinoma of the maxillary sinus: a Tata Memorial Hospital experience. Indian J Cancer 2006;43[1]:26-9.

33. Katz TS, Mendenhall WM, Morris CG, Amdur RJ, Hinerman RW, Villaret DB. Malignant tumors of the nasal cavity and paranasal sinuses. Head Neck 2002;24[9]:821-9.

34. Lund VJ, Clarke PM, Swift AC, McGarry GW, Kerawala C, Carnell D. Nose and paranasal sinus tumors: United Kingdom National Multidisciplinary Guidelines. J Laryngol Otol 2016;130[S2]:S111-8.

35. Kalavrezos N, Bhandari R. Current trends and future perspectives in the surgical management of oral cancer. Oral Oncol 2010;46[6]:429-32.

36. McGregor AD, MacDonald DG. Routes of entry of squamous cell carcinoma to the mandible. Head Neck Surg 1988;10[5]:294-301.

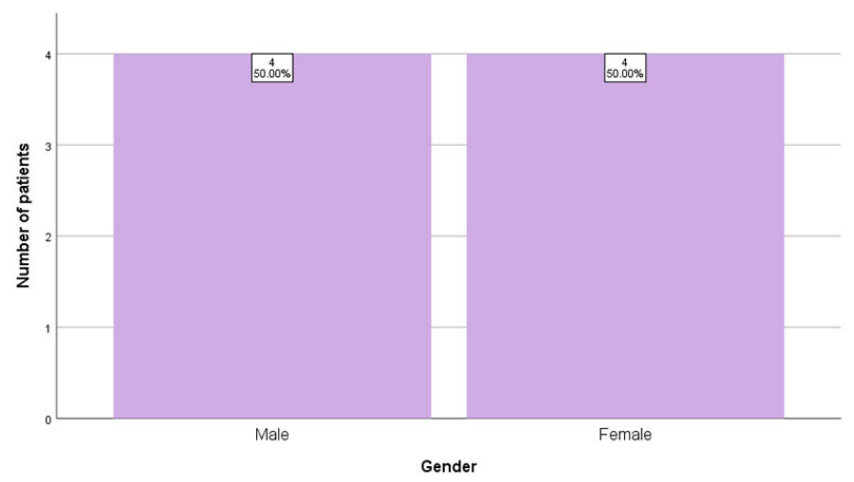

Graph 2: Bar chart showing the gender distribution of maxillary carcinoma patients. $X$ axis represents the gender and $Y$ axis represents the number of patients. We found that both male and female patients are equally affected with maxillary carcinoma. 


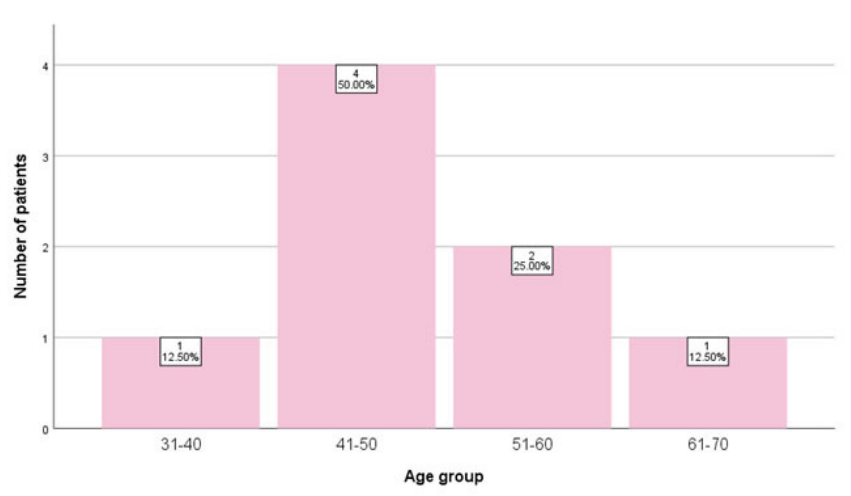

Graph 3: Bar chart showing the age distribution among maxillary carcinoma patients. $X$ axis represents the age and $Y$ axis represents the number of patients. We found that higher incidence of maxillary carcinoma was seen in the age group $41-50[50.00 \%$ ] followed by 51-60 age group [25.00\%]

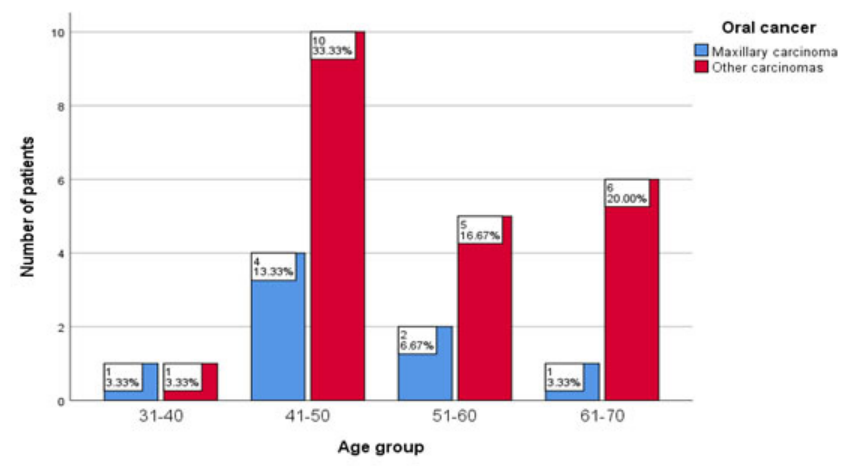

Graph 4: This Graph represents the association between age and maxillary carcinoma $X$ axis represents age and $Y$ axis represents number of patients. Blue colour denotes maxillary carcinoma and red colour denotes other carcinomas. Association was done between age and maxillary carcinoma using Chi-square test [ $p$-value $=0.766]$ and was found to be statistically not significant.

Table 1: Shows chi square test between age and maxillary carcinoma patients which was found to be statistically not significant

\begin{tabular}{lccc}
\multicolumn{4}{c}{ Chi-Square Tests } \\
& Value & df & $\begin{array}{c}\text { Asymptotic Significance } \\
\text { [2-sided] }\end{array}$ \\
Pearson Chi-Square & $1.144^{\mathrm{a}}$ & 3 & .766 \\
Likelihood Ratio & 1.153 & 3 & .764 \\
N of Valid Cases & 30 & & \\
\hline
\end{tabular}

a. 5 cells $[62.5 \%]$ have expected counts less than 5 . The minimum expected count is 0.53 .

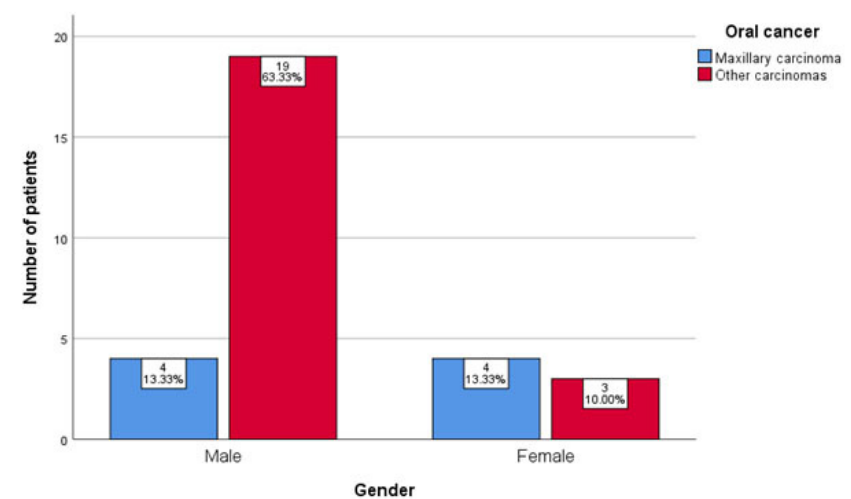

Graph 5: This Graph represents the association between gender and maxillary carcinoma.

$\mathrm{X}$ axis represents gender and $\mathrm{Y}$ axis represents the number of patients. Blue colour denotes maxillary carcinoma and red colour denotes other carcinomas. Association was analysed between gender and maxillary carcinoma using Chi-square test $[\mathrm{p}$-value $=0.037]$ and was found to be statistically significant.

\section{Chi-Square Tests}

Table 2: Shows chi square test between gender and maxillary carcinoma patients which was found to be statistically significant

\begin{tabular}{lccccc} 
& Value df & $\begin{array}{c}\text { Asymp- } \\
\text { totic Sig- } \\
\text { nificance } \\
\text { [2-sided] }\end{array}$ & $\begin{array}{c}\text { Exact } \\
\text { [2-sided] }\end{array}$ & $\begin{array}{c}\text { Exact } \\
\text { Sig. } \\
\text { [1-sided] }\end{array}$ \\
$\begin{array}{l}\text { Pearson Chi- } \\
\text { Square }\end{array}$ & $4.337^{\mathrm{a}}$ & 1 & .037 & \\
$\begin{array}{l}\text { Continuity } \\
\text { Correction }\end{array}$ & 2.542 & 1 & .111 & & \\
$\begin{array}{l}\text { Likelihood } \\
\text { Ratio }\end{array}$ & 3.980 & 1 & .046 & \\
$\begin{array}{l}\text { Fisher's Exact } \\
\text { Test }\end{array}$ & & & & & \\
$\begin{array}{l}\text { N of Valid } \\
\text { Cases }\end{array}$ & 30 & & & & \\
\hline
\end{tabular}

a. 1 cells $[25.0 \%]$ have expected count less than 5 . The minimum expected count is 1.87 .

b. Computed only for a $2 \times 2$ table 